Preprints of the

Max Planck Institute for

Research on Collective Goods

Bonn 2009/32

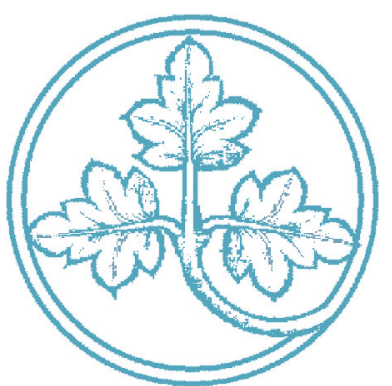

Beyond the Need to Boast:

Cost Concealment

Incentives and Exit in

Cournot Duopoly

Jos Jansen

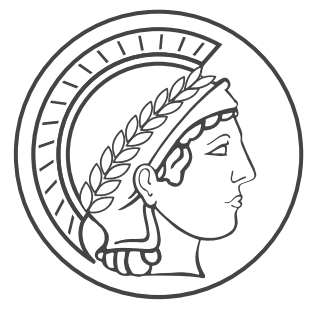




\section{Beyond the Need to Boast: Cost Concealment Incentives and Exit in Cournot Duopoly}

Jos Jansen

September 2009 


\title{
Beyond the Need to Boast: Cost Concealment Incentives and Exit in Cournot Duopoly*
}

\author{
Jos Jansen \\ Max Planck Institute for Research on Collective Goods ${ }^{\dagger}$
}

September 2009

\begin{abstract}
This paper studies the incentives for production cost disclosure in an asymmetric Cournot duopoly. Whereas the efficient firm (consumers) prefers information sharing (concealment) when the firms choose accommodating strategies in the product market, the firm (consumers) may prefer information concealment (sharing) when it can exclude its competitor from the market. Hence, the rankings of expected profit and consumer surplus can be reversed if exit of the inefficient firm is possible. Although the efficient firm has stronger incentives to share information when it shares strategically, there remain cases in which the firm conceals information in equilibrium to induce exit.
\end{abstract}

Keywords: Cournot duopoly, information disclosure, exit, cost asymmetry, precommitment JEL Codes: D82, L13

${ }^{*}$ I thank Carsten Burhop, Christoph Engel, Luigi Filippini, Martin Hellwig, Felix Höffler, and Andreas Nicklisch for helpful discussions and comments. All errors are mine.

${ }^{\dagger}$ Address: Kurt-Schumacher-Str. 10, D-53113 Bonn, Germany; E-mail: <jansen@coll.mpg.de> 


\section{Introduction}

Non-colluding Cournot competitors have an incentive to share information about independent production costs, if they use accommodating output strategies in the product market (Fried, 1984, Gal-Or, 1986, and Shapiro, 1986). In this case, information sharing decreases the expected consumer surplus (Shapiro, 1986).

This paper shows that these result depend on the presumption that firms use accommodating strategies in the product market. The previous results may be reversed when firms do not always use accommodating strategies. If a firm's average technology is sufficiently productive to exclude a competitor from the market, then the firm no longer has an incentive to share cost information. In such a case a firm with below-average costs will be indifferent between information sharing and information concealment, since in any case the firm excludes its competitor from the market. A firm with high costs may strictly prefer to conceal its cost, since it avoids sharing the market with the competitor by doing so.

If cost concealment yields market exclusion, then it may be harmful for consumers, since it raises the average price, and eliminates product variety. In this case information sharing would make consumers better off on average. In short, also the surplus ranking may be reversed if exclusionary outputs are feasible for a firm.

The paper is organized as follows. In the next section I describe the model. The third section discusses the equilibrium strategies (i.e., output levels, and information disclosure), and compares the expected consumer surplus under information sharing and concealment. Section 4 analyzes the incentives of a firm that discloses information strategically. Finally, section 5 concludes the paper. The proofs of the propositions are relegated to the Appendix.

\section{The Model}

Two risk-neutral firms play a game with three stages. Firm 1 has private information about its cost of production, $\theta_{1}$. Firm 2's cost, $\theta_{2}$, is common knowledge.

In the first stage, before firm 1 learns its cost, the firm chooses whether to share the cost information, i.e., $d\left(\theta_{1}\right)=\theta_{1}$ for all $\theta_{1} \in[\underline{\theta}, \bar{\theta}]$, or to keep it secret and send an uninformative message, i.e., $d\left(\theta_{1}\right)=\varnothing$ for all $\theta_{1} \in[\underline{\theta}, \bar{\theta}] .{ }^{1}$

\footnotetext{
${ }^{1}$ The assumptions that firms precommit to an information sharing rule, and that information is verifiable, are common in the literature on oligopolistic information sharing (e.g., see Kühn and Vives, 1995, and Vives, 1999, for surveys). Adopting the same assumptions facilitates the comparison
} 
Subsequently, in the second stage, firm 1 draws a cost $\theta_{1} \in[\underline{\theta}, \bar{\theta}]$ from p.d.f. $f:[\underline{\theta}, \bar{\theta}] \rightarrow \mathbb{R}_{+}$(and corresponding c.d.f. $F:[\underline{\theta}, \bar{\theta}] \rightarrow[0,1]$ ) with full support (i.e., $f\left(\theta_{1}\right)>0$ for all $\left.\theta_{1} \in[\underline{\theta}, \bar{\theta}]\right)$, and discloses or conceals the cost parameter in accordance with the first-stage choice.

Finally, in the third stage, the firms compete in the product market. The firms simultaneously choose their output levels, $x_{i} \geq 0$ for firm $i$ with $i=1,2$ (Cournot competition).

The representative consumer's utility from consuming bundle $\left(x_{1}, x_{2}\right)$ is:

$$
U\left(x_{1}, x_{2}\right) \equiv \alpha\left(x_{1}+x_{2}\right)-\frac{1}{2}\left(x_{1}^{2}+2 \beta x_{1} x_{2}+x_{2}^{2}\right) .
$$

Hence, the inverse demand for the good of firm $i$ is linear, i.e. $P_{i}\left(\mathbf{x}_{i}\right)=\alpha-x_{i}-\beta x_{j}$, where $\mathbf{x}_{i} \equiv\left(x_{i}, x_{j}\right)$ is the bundle of outputs of firms $i$ and $j$, respectively, and $i, j \in$ $\{1,2\}$ with $i \neq j$. Parameter $\beta$ represents the degree of product substitutability, with $0<\beta \leq 1$. The profit of firm $i$ with $\operatorname{cost} \theta_{i}$ is $(i, j \in\{1,2\}$ with $i \neq j)$ :

$$
\pi_{i}\left(\mathbf{x}_{i} ; \theta_{i}\right)=\left(\alpha-x_{i}-\beta x_{j}-\theta_{i}\right) x_{i} .
$$

The consumer surplus from consumption of $\left(x_{1}, x_{2}\right)$ equals:

$$
S\left(x_{1}, x_{2}\right)=\frac{1}{2}\left(x_{1}^{2}+2 \beta x_{1} x_{2}+x_{2}^{2}\right)
$$

The parameter values should satisfy the following conditions:

$$
3 \alpha>4 \bar{\theta}-\underline{\theta}
$$

and

$$
\widetilde{\theta}(\underline{\theta})<\theta_{2}<\tilde{\theta}(\bar{\theta})
$$

where (for $\left.\theta_{1} \in[\underline{\theta}, \bar{\theta}]\right) \tilde{\theta}$ is defined as

$$
\widetilde{\theta}\left(\theta_{1}\right) \equiv \frac{1}{2}\left((2-\beta) \alpha+\beta \theta_{1}\right)
$$

Conditions (4)-(5) guarantee that firm 1 is always active in the market. Condition (5) guarantees that exclusion of firm 2 happens in some but not all of the cases. ${ }^{2}$

I solve the game backwards, and restrict the analysis to perfect Bayesian equilibria.

with existing results. Section 4 analyzes the extension where firm 1 makes the information sharing choice after it learns the cost realization.

${ }^{2}$ By contrast, if $\theta_{2} \leq \tilde{\theta}(\underline{\theta})$, then the standard analysis applies. Both firms choose accomodating output strategies, and firm 1 shares all information in the unique equilibrium in dominant strategies. Further, if $\theta_{2} \geq \tilde{\theta}(\bar{\theta})$, then firm 2 never has an incentive to produce, and therefore information discosure has no effect on firm 1's profit. Consequently, firm 1 is indifferent between information sharing and information concealment. 


\section{$3 \quad$ Equilibrium Strategies}

In this section I solve the model backwards. First, I characterize the firms' output strategies. Second, I compare firm 1's profit and the consumer surplus under information sharing and concealment.

\subsection{Output Strategies}

Distinguish two cases. First, suppose that firm 1 shares information. Profit-maximization by firm $i$ gives the following first-order condition (for $i, j=1,2$ and $i \neq j$ ):

$$
x_{i}\left(x_{j} ; \theta_{i}\right)= \begin{cases}\frac{1}{2}\left(\alpha-\theta_{i}-\beta x_{j}\right), & \text { if } 0 \leq x_{j} \leq \frac{1}{\beta}\left(\alpha-\theta_{i}\right) \\ 0, & \text { otherwise }\end{cases}
$$

Firms 1 and 2 choose the following output levels in equilibrium (for $\theta_{1} \in[\underline{\theta}, \bar{\theta}]$ ):

$$
x_{1}^{*}\left(\theta_{1}, \theta_{2}\right)= \begin{cases}x^{d}\left(\theta_{1}, \theta_{2}\right), & \text { if } \theta_{2} \leq \tilde{\theta}\left(\theta_{1}\right) \\ x^{m}\left(\theta_{1}\right), & \text { if } \theta_{2}>\widetilde{\theta}\left(\theta_{1}\right)\end{cases}
$$

and

$$
x_{2}^{*}\left(\theta_{2}, \theta_{1}\right)= \begin{cases}x^{d}\left(\theta_{2}, \theta_{1}\right), & \text { if } \theta_{2} \leq \widetilde{\theta}\left(\theta_{1}\right) \\ 0, & \text { if } \theta_{2}>\widetilde{\theta}\left(\theta_{1}\right)\end{cases}
$$

where (for $i, j=1,2$ and $i \neq j$ ) the duopoly and monopoly outputs are defined as

$$
\begin{aligned}
x^{d}\left(\theta_{i}, \theta_{j}\right) & \equiv \frac{1}{4-\beta^{2}}\left((2-\beta) \alpha-2 \theta_{i}+\beta \theta_{j}\right) \\
x^{m}\left(\theta_{1}\right) & \equiv \frac{1}{2}\left(\alpha-\theta_{1}\right)
\end{aligned}
$$

Second, if firm 1 does not share information about its cost, then firm 2 expects the cost $E\left\{\theta_{1}\right\}$ of firm 1. Profit maximization by firm 1 gives the best-response function $x_{1}\left(x_{2} ; \theta_{1}\right)$ as in (7). The best-response of firms 2 is $x_{2}\left(E\left\{x_{1}\left(\theta_{1}\right)\right\} ; \theta_{2}\right)$ as in (7). After concealment the equilibrium output levels of firm 1 and 2 are, respectively:

$$
x_{1}^{o}\left(\theta_{1}, \theta_{2} ; E\left\{\theta_{1}\right\}\right)= \begin{cases}x^{d}\left(\theta_{1}, \theta_{2}\right)+\frac{\beta^{2}\left(\theta_{1}-E\left\{\theta_{1}\right\}\right)}{2\left(4-\beta^{2}\right)}, & \text { if } \theta_{2} \leq \tilde{\theta}\left(E\left\{\theta_{1}\right\}\right) \\ x^{m}\left(\theta_{1}\right), & \text { if } \theta_{2}>\widetilde{\theta}\left(E\left\{\theta_{1}\right\}\right)\end{cases}
$$

and $x_{2}^{o}\left(\theta_{2} ; E\left\{\theta_{1}\right\}\right) \equiv x_{2}^{*}\left(\theta_{2}, E\left\{\theta_{1}\right\}\right)$ with $x_{2}^{*}$ as in (9).

In any situation the expected equilibrium product market profit is: $\pi_{i}^{k}(\cdot)=x_{i}^{k}(\cdot)^{2}$. 


\subsection{Information Sharing}

Now I solve the first stage of the game where firm 1 chooses whether to share or conceal information about its cost before it learns the cost $\theta_{1}$.

The expected profit from precommitment to information sharing equals:

$$
\Pi_{1}^{*}\left(\theta_{2}\right)=\int_{\underline{\theta}}^{\widetilde{\theta}^{-1}\left(\theta_{2}\right)} \pi^{m}(y) d F(y)+\int_{\tilde{\theta}^{-1}\left(\theta_{2}\right)}^{\bar{\theta}} \pi^{d}\left(z, \theta_{2}\right) d F(z)
$$

where $\widetilde{\theta}^{-1}\left(\theta_{2}\right) \equiv\left[2 \theta_{2}-(2-\beta) \alpha\right] / \beta$ is the inverse of $\widetilde{\theta}(\cdot)$. Firm 2 conditions its output choice on the information about the cost of firm 1 . If firm 1 is relatively efficient (i.e., $\left.\theta_{1} \leq \widetilde{\theta}^{-1}\left(\theta_{2}\right)\right)$, then firm 2 exits, and firm 1 earns the monopoly profit $\pi^{m}$. If, on the other hand, firm 1 is less efficient (i.e., $\theta_{1}>\widetilde{\theta}^{-1}\left(\theta_{2}\right)$ ), then the firms choose accommodating output strategies, and firm 1 earns the duopoly profit $\pi^{d}$.

The expected profit from concealment equals:

$$
\Pi_{1}^{o}\left(\theta_{2}\right)= \begin{cases}E\left\{\left(x^{d}\left(\theta_{1}, \theta_{2}\right)+\frac{\beta^{2}\left(\theta_{1}-E\left\{\theta_{1}\right\}\right)}{2\left(4-\beta^{2}\right)}\right)^{2}\right\}, & \text { if } \widetilde{\theta}(\underline{\theta}) \leq \theta_{2}<\widetilde{\theta}\left(E\left\{\theta_{1}\right\}\right) \\ E\left\{\pi^{m}\left(\theta_{1}\right)\right\}, & \text { if } \widetilde{\theta}\left(E\left\{\theta_{1}\right\}\right) \leq \theta_{2}<\tilde{\theta}(\bar{\theta})\end{cases}
$$

After information concealment firm 2 cannot condition its output on the actual cost of firm 1, but needs to rely on the expected cost. If firm 2's cost is sufficiently low in comparison with firm 1's average cost (i.e., $\theta_{2}<\tilde{\theta}\left(E\left\{\theta_{1}\right\}\right)$ ), then the firms choose accommodating outputs, and firm 1 earns (distorted) duopoly profits for all cost parameters $\theta_{1} \in[\underline{\theta}, \bar{\theta}]$. If the cost $\theta_{2}$ is equal to or above $\widetilde{\theta}\left(E\left\{\theta_{1}\right\}\right)$, then firm 2 exits the market and firm 1 earns the monopoly profit for all cost parameters $\theta_{1}$.

The comparison of these expected-profit functions gives the following result.

Proposition 1 There exists a critical $\theta^{o}$, with $\widetilde{\theta}(\underline{\theta})<\theta^{o}<\widetilde{\theta}\left(E\left\{\theta_{1}\right\}\right)$, such that firm 1 conceals information in equilibrium if and only if $\theta^{\circ}<\theta_{2}<\widetilde{\theta}(\bar{\theta})$.

The intuition for this result is simple. If the cost of firm 2 is sufficiently high (i.e., $\left.\theta_{2} \geq \tilde{\theta}\left(E\left\{\theta_{1}\right\}\right)\right)$, then firm 1 can earn the monopoly profit for any cost parameter $\theta_{1}$ by choosing cost concealment, since firm 2 exits the market under information concealment. Firm 1 expects a lower profit from information sharing, since it cannot always exclude firm 2 from the market under information sharing. In particular, the firm earns duopoly profits after it shares information about relatively high costs, i.e., $\theta_{1}>\widetilde{\theta}^{-1}\left(\theta_{2}\right)$. Therefore, the firm prefers cost concealment.

If the firm 2's cost is lower than $\widetilde{\theta}\left(E\left\{\theta_{1}\right\}\right)$, then firm 1 faces the following trade-off. On the one hand, information sharing makes firm 2 a more "aggressive" competitor 
(i.e., $\left.x_{2}^{*}\left(\theta_{2} ; \theta_{1}\right)>x_{2}^{o}\left(\theta_{2} ; E\left\{\theta_{1}\right\}\right)\right)$, if firm 1 has a cost parameter $\theta_{1}>E\left\{\theta_{1}\right\}$. On the other hand, firm 2 becomes less "aggressive" in the product market after information sharing, i.e., $x_{2}^{*}\left(\theta_{2} ; \theta_{1}\right)<x_{2}^{o}\left(\theta_{2} ; E\left\{\theta_{1}\right\}\right)$, if $\theta_{1}<E\left\{\theta_{1}\right\}$. The gain from information sharing is truncated, since firm 2 exits the market when firm 1 has the most efficient cost parameters (i.e., $\left.\theta_{1} \leq \widetilde{\theta}^{-1}\left(\theta_{2}\right)\right)$. Therefore, the former effect outweighs the latter, if $\theta_{2}$ is sufficiently close to $\tilde{\theta}\left(E\left\{\theta_{1}\right\}\right)$.

The profit ranking of Proposition 1 differs dramatically from the ranking of a firm that uses accommodating output strategies in the product market. Whereas a firm has an incentive to share information when the firms choose accommodating output strategies (e.g., see Fried, 1984, Gal-Or, 1986, and Shapiro, 1986), the firm has an incentive to conceal information when exit matters.

Figure 1 illustrates the effects of information sharing through the equilibrium outputs. The thin lines are the best response curves of firm 1. The bold lines are the

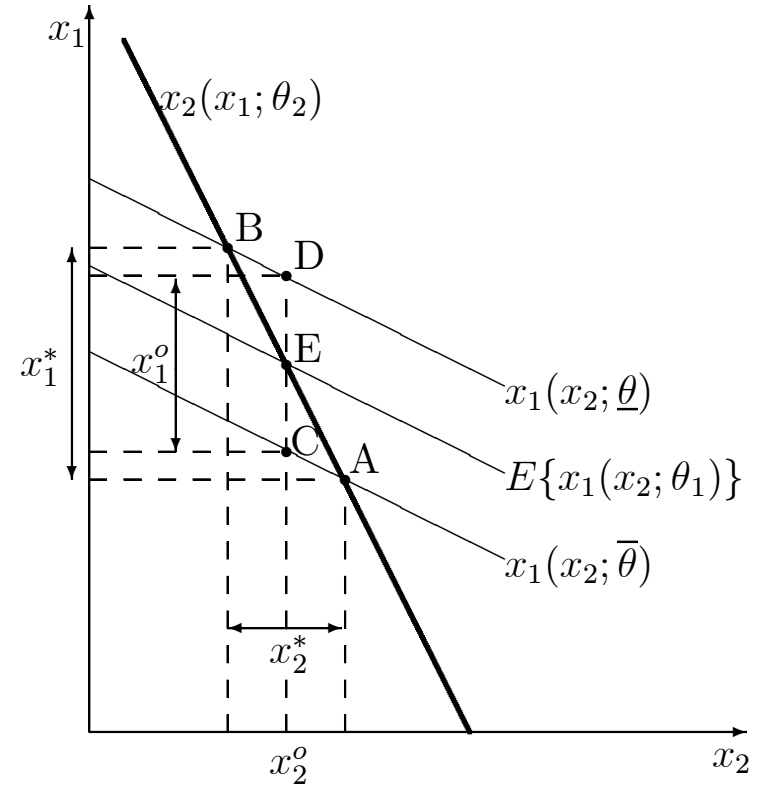

Fig. 1(a): Accommodation

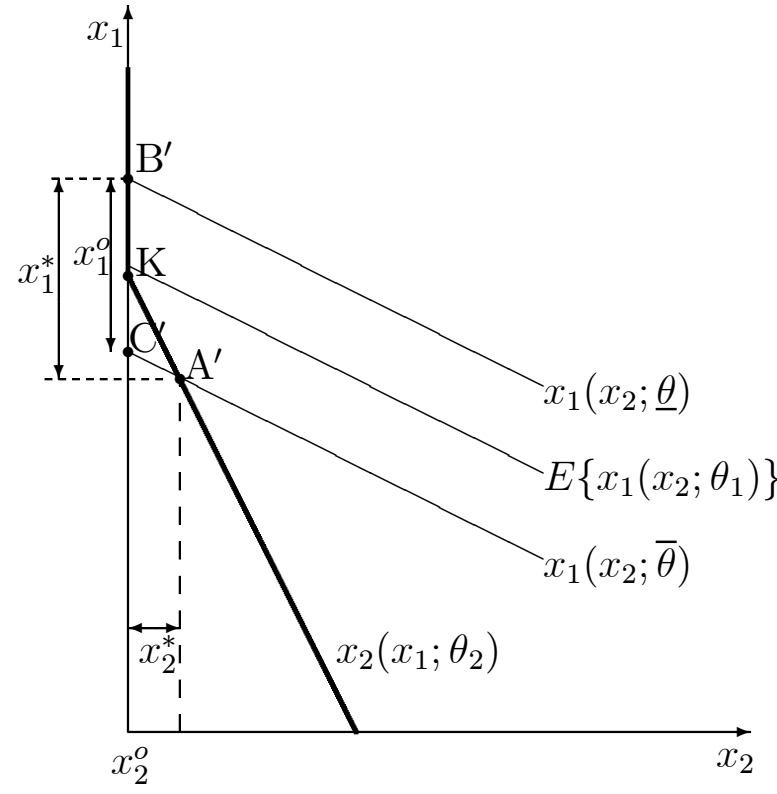

Fig. 1(b): Exclusion

Figure 1: Effects of information sharing

best response curves of firm 2. First, Figure 1(a) illustrates the effects for accommodating firms. Information disclosure enables firm 2 to adjust its output levels to the actual efficiency level of firm 1. The equilibrium outputs lie along the line A-B. For example, if firm 1 discloses the highest (lowest) cost level, then the equilibrium is reached in point $\mathrm{A}(\mathrm{B})$. After cost concealment, firm 2 sets output level $x_{2}^{o}$, which is the best response to firm 1's expected output level (point E in Figure 1a). Firm 1's 
best response to output level $x_{2}^{o}$ gives equilibrium output levels along the line C-D. Information sharing increases firm 1's expected profit, since it creates a mean-preserving spread, and profits are convex in the firm's output level.

Second, Figure 1(b) illustrates the effects of information sharing when firm 1 can exclude its competitor from the market if $\theta_{1}$ is low. Again, disclosure yields some output adjustments by firm 2, i.e., the firms set equilibrium outputs along the kinked line A'-K-B'. Firm 2's output adjustments create a spread of firm 1's output levels corresponding to the vertical distance between $\mathrm{A}^{\prime}$ and $\mathrm{B}^{\prime}$. Information concealment excludes firm 2 from the market (i.e., $x_{2}^{o}=0$ ), and creates a smaller spread of firm 1's outputs (i.e., outputs along the line $\mathrm{B}^{\prime}-\mathrm{C}^{\prime}$ ). Even tough information sharing creates a bigger output spread for firm 1 , it does not increase the firm's expected profit. This is the case since information disclosure reduces firm 1's average output. In other words, the mean is not preserved.

The comparison of consumer surplus under full and no information sharing is similar. The consumer surplus under information sharing equals:

$$
S^{*}\left(\theta_{2}\right)=\int_{\underline{\theta}}^{\widetilde{\theta}^{-1}\left(\theta_{2}\right)} S\left(x^{m}(y), 0\right) d F(y)+\int_{\widetilde{\theta}^{-1}\left(\theta_{2}\right)}^{\bar{\theta}} S\left(x^{d}\left(z, \theta_{2}\right), x^{d}\left(\theta_{2}, z\right)\right) d F(z)
$$

The consumer surplus under information concealment equals:

$S^{o}\left(\theta_{2}\right)= \begin{cases}E\left\{S\left(x^{d}\left(\theta_{1}, \theta_{2}\right)+\frac{\beta^{2}\left(\theta_{1}-E\left\{\theta_{1}\right\}\right)}{2\left(4-\beta^{2}\right)}, x^{d}\left(\theta_{2}, E\left\{\theta_{1}\right\}\right)\right)\right\}, & \text { if } \tilde{\theta}(\underline{\theta}) \leq \theta_{2}<\tilde{\theta}\left(E\left\{\theta_{1}\right\}\right) \\ E\left\{S\left(x^{m}\left(\theta_{1}\right), 0\right)\right\}, & \text { if } \widetilde{\theta}\left(E\left\{\theta_{1}\right\}\right) \leq \theta_{2}<\tilde{\theta}(\bar{\theta})\end{cases}$

Comparing these surpluses gives the following result:

Proposition 2 There exists a critical $\theta^{*}$, with $\widetilde{\theta}(\underline{\theta})<\theta^{*}<\widetilde{\theta}\left(E\left\{\theta_{1}\right\}\right)$, such that the expected consumer surplus is higher with information sharing if $\theta^{*}<\theta_{2}<\tilde{\theta}(\bar{\theta})$, and higher without information sharing otherwise.

The intuition is similar to the intuition for Proposition 1. If $\theta_{2} \geq \widetilde{\theta}\left(E\left\{\theta_{1}\right\}\right)$, then information concealment yields exit of firm 2 for all $\theta_{1}$. Information sharing yields accommodation for sufficiently inefficient technologies of firm 1 (i.e., $\theta_{1}>\widetilde{\theta}^{-1}\left(\theta_{2}\right)$ ). This increases the consumer surplus, since outputs expand, and product variety increases. If $\theta_{2}$ is slightly lower than $\tilde{\theta}\left(E\left\{\theta_{1}\right\}\right)$, an analogous intuition applies: information sharing expands the average output levels, and thereby increases expected consumer surplus. 
In models where firms choose accommodating output strategies the expected consumer surplus is highest under information concealment (Shapiro, 1986). The proposition shows that the surplus ranking is reversed when firm 2's incentive to exit is affected by information sharing.

\section{Strategic Information Disclosure}

In this section I characterize firms' interim information disclosure incentives. That is, firm 1 chooses a disclosure rule $d\left(\theta_{1}\right) \in\left\{\theta_{1}, \varnothing\right\}$ after it privately learns the cost $\theta_{1}$ for any $\theta_{1} \in[\underline{\theta}, \bar{\theta}]$. The equilibrium outputs after disclosure of $\theta_{1}$ are as in (8)-(9). If firm 1 does not disclose its cost, then firm 2 expects the cost $E\left\{\theta_{1} \mid \varnothing\right\}$ of firm 1 . The equilibrium outputs are then as in (12) with $E\left\{\theta_{1}\right\}$ replaced by $E\left\{\theta_{1} \mid \varnothing\right\}$, and $x_{2}^{o}\left(\theta_{2} ; E\left\{\theta_{1} \mid \varnothing\right\}\right) \equiv x_{2}^{*}\left(\theta_{2}, E\left\{\theta_{1} \mid \varnothing\right\}\right)$.

First, I show that there always exists an equilibrium with full disclosure.

Proposition 3 There always exists an equilibrium in which firm 1 discloses all information, i.e., $d\left(\theta_{1}\right)=\theta_{1}$ for any $\theta_{1} \in[\underline{\theta}, \bar{\theta}]$.

A full disclosure equilibrium exists if firm 2 holds skeptical beliefs, i.e. $E\left\{\theta_{1} \mid \varnothing\right\}=$ $\bar{\theta}$. Given these beliefs, firm 1 has an incentive to disclose its cost $\theta_{1}$ for all $\theta_{1} \in[\underline{\theta}, \bar{\theta}]$, since it discourages output production by the competitor (i.e., $x_{2}^{*}\left(\theta_{2}, \theta_{1}\right)<x_{2}^{o}\left(\theta_{2} ; \bar{\theta}\right)$ for all $\theta_{1}<\bar{\theta}$ ). This is a standard unraveling result (Grossman, 1981, Milgrom, 1981, and Okuno-Fujiwara et al., 1990). However, this equilibrium is not always unique.

In spite of the fact that the incentive to disclose information is stronger than in the model with precommitment, there remain cases in which it is optimal for firm 1 to conceal. In particular, I find the following for sufficiently high costs of firm 2 .

Proposition 4 If $\tilde{\theta}\left(E\left\{\theta_{1}\right\}\right) \leq \theta_{2}<\tilde{\theta}(\bar{\theta})$, then for any subset $\mathcal{D}$ of the interval $\left[\underline{\theta}, \widetilde{\theta}^{-1}\left(\theta_{2}\right)\right]$ such that $E\left\{\theta_{1} \mid \theta_{1} \notin \mathcal{D}\right\} \leq \widetilde{\theta}^{-1}\left(\theta_{2}\right)$ the following disclosure rule is an equilibrium rule:

$$
d\left(\theta_{1}\right)= \begin{cases}\theta_{1}, & \text { if } \theta_{1} \in \mathcal{D} \\ \varnothing, & \text { otherwise }\end{cases}
$$

The proposition has the following immediate implication.

Corollary 1 If $\widetilde{\theta}\left(E\left\{\theta_{1}\right\}\right) \leq \theta_{2}<\tilde{\theta}(\bar{\theta})$, then an equilibrium exists in which firm 1 keeps any cost secret, i.e. $d\left(\theta_{1}\right)=\varnothing$ for all $\theta_{1} \in[\underline{\theta}, \bar{\theta}]$. 
Proof. If $\mathcal{D}=\emptyset$, then $E\left\{\theta_{1} \mid \theta_{1} \notin \mathcal{D}\right\}=E\left\{\theta_{1}\right\} \leq \widetilde{\theta}^{-1}\left(\theta_{2}\right)$, since $\widetilde{\theta}\left(E\left\{\theta_{1}\right\}\right) \leq \theta_{2}$.

If $\widetilde{\theta}\left(E\left\{\theta_{1}\right\}\right) \leq \theta_{2}<\widetilde{\theta}(\bar{\theta})$, and firm 2 has beliefs consistent with full concealment (i.e., $E\left\{\theta_{1} \mid \varnothing\right\}=E\left\{\theta_{1}\right\}$ ), then firm 1 has an incentive to keep any cost secret. Given these beliefs firm 2 exits the market, if firm 1 conceals its cost. By contrast, disclosure would yield accommodating output strategies (i.e., $x_{2}^{*}\left(\theta_{2}, \theta_{1}\right)>0=x_{2}^{o}\left(\theta_{2} ; E\left\{\theta_{1}\right\}\right)$ ), if firm 1 is less efficient than expected (i.e., $\left.\theta_{1}>E\left\{\theta_{1}\right\}\right)$. It yields exclusion of firm 2 , if firm 1 is more efficient than expected (i.e., $\theta_{1} \leq E\left\{\theta_{1}\right\}$ ). In other words, cost concealment gives firm 1 profits which are greater than or equal to the profits under disclosure.

A comparison of the profits from the disclosure rules in Propositions 3 and 4 gives the following. The firm's profit from full disclosure is $\pi_{1}^{*}\left(\theta_{1}, \theta_{2}\right)$. Under the conditions of Proposition 4, firm 1's profits from disclosure rule (17) are $\pi_{1}^{o}\left(\theta_{1}, \theta_{2} ; E\left\{\theta_{1} \mid \theta_{1} \notin \mathcal{D}\right\}\right)$. The profit from disclosure rule (17) is greater than or equal to the profit from full disclosure, i.e., $\pi_{1}^{o}\left(\theta_{1}, \theta_{2} ; E\left\{\theta_{1} \mid \theta_{1} \notin \mathcal{D}\right\}\right) \geq \pi_{1}^{*}\left(\theta_{1}, \theta_{2}\right)$ for any $\theta_{1}$ and $\widetilde{\theta}\left(E\left\{\theta_{1}\right\}\right) \leq \theta_{2}<$ $\widetilde{\theta}(\bar{\theta})$, since firm 2 is excluded more often from the market under disclosure rule (17).

\section{Conclusion}

I characterized the conditions under which a firm keeps its cost of production secret in a Cournot duopoly. The possibility of exit by a competitor may give the firm an incentive for secrecy. Whereas a firm typically prefers to share information about independent cost parameters when the firms choose accommodating output strategies in the product market, the firm may prefer to conceal cost information in cases where its competitor can be excluded from the market. This result holds not only in a setting where the firm precommits to share information, but also (though in fewer cases, and not uniquely) in a setting in which the firm makes a strategic disclosure choice.

The possibility of exit also affects the expected consumer surplus ranking. In cases where exit occurs consumers may on average be better off under information sharing. By contrast, consumers prefer the equilibrium allocation under information concealment, when firms choose accommodating output strategies in the product market.

A possible extension to the analysis could be to introduce incomplete information about firm 2's cost. The paper's results would still hold if firm 2's cost is randomly drawn from an interval with inefficient technologies (e.g., $\theta_{2} \in\left[\max \left\{\theta^{o}, \theta^{*}\right\}, \widetilde{\theta}(\bar{\theta})\right]$ ).

These observations provide a caveat for antitrust policy towards information sharing in industries with asymmetric firms. 


\section{A Appendix}

This Appendix provides proofs to the propositions.

\section{Proof of Proposition 1}

First, if $\widetilde{\theta}\left(E\left\{\theta_{1}\right\}\right) \leq \theta_{2}<\widetilde{\theta}(\bar{\theta})$, then $\Pi_{1}^{o}\left(\theta_{2}\right)>\Pi_{1}^{*}\left(\theta_{2}\right)$, since $\pi^{m}\left(\theta_{1}\right)>\pi_{1}^{d}\left(\theta_{1}, \theta_{2}\right)$ for all $\theta_{1}>\widetilde{\theta}^{-1}\left(\theta_{2}\right)$. Second, take $\tilde{\theta}(\underline{\theta}) \leq \theta_{2}<\tilde{\theta}\left(E\left\{\theta_{1}\right\}\right)$. The first derivative of $\Pi_{1}^{*}\left(\theta_{2}\right)$ equals:

$$
\begin{aligned}
\frac{d \Pi_{1}^{*}\left(\theta_{2}\right)}{d \theta_{2}}= & \frac{\tilde{d}^{-1}\left(\theta_{2}\right)}{d \theta_{2}}\left[x^{m}\left(\widetilde{\theta}^{-1}\left(\theta_{2}\right)\right)^{2}-x^{d}\left(\widetilde{\theta}^{-1}\left(\theta_{2}\right), \theta_{2}\right)^{2}\right] f\left(\widetilde{\theta}^{-1}\left(\theta_{2}\right)\right) \\
& +\int_{\tilde{\theta}^{-1}\left(\theta_{2}\right)}^{\bar{\theta}} 2 \frac{\partial x^{d}\left(z, \theta_{2}\right)}{\partial \theta_{2}} x^{d}\left(z, \theta_{2}\right) d F(z) \\
= & \frac{2 \beta}{4-\beta^{2}} \int_{\tilde{\theta}^{-1}\left(\theta_{2}\right)}^{\bar{\theta}} x^{d}\left(z, \theta_{2}\right) d F(z)
\end{aligned}
$$

since $x^{m}\left(\widetilde{\theta}^{-1}\left(\theta_{2}\right)\right)=x^{d}\left(\widetilde{\theta}^{-1}\left(\theta_{2}\right), \theta_{2}\right)$. Taking the first derivative of $\Pi_{1}^{o}\left(\theta_{2}\right)$ yields:

$$
\begin{aligned}
\frac{d \Pi_{1}^{o}\left(\theta_{2}\right)}{d \theta_{2}} & =\int_{\underline{\theta}}^{\bar{\theta}} 2 \frac{\partial x^{d}\left(z, \theta_{2}\right)}{\partial \theta_{2}}\left(x^{d}\left(z, \theta_{2}\right)+\frac{\beta^{2}\left(z-E\left\{\theta_{1}\right\}\right)}{2\left(4-\beta^{2}\right)}\right) d F(z) \\
& =\frac{2 \beta}{4-\beta^{2}} \int_{\underline{\theta}}^{\bar{\theta}} x^{d}\left(z, \theta_{2}\right) d F(z)
\end{aligned}
$$

The comparison of first derivatives gives immediately $d \Pi_{1}^{o}\left(\theta_{2}\right) / d \theta_{2}>d \Pi_{1}^{*}\left(\theta_{2}\right) / d \theta_{2}$. The evaluation of the expected-profit functions for extreme values of firm 2's cost gives the following:

$$
\begin{aligned}
\Pi_{1}^{*}\left(\widetilde{\theta}\left(E\left\{\theta_{1}\right\}\right)\right) & =\int_{\underline{\theta}}^{E\left\{\theta_{1}\right\}} \pi^{m}(\theta) d F(\theta)+\int_{E\left\{\theta_{1}\right\}}^{\bar{\theta}} \pi^{d}\left(z, \theta_{2}\right) d F(z) \\
& <\int_{\underline{\theta}}^{\bar{\theta}} \pi^{m}(z) d F(z)=\Pi_{1}^{o}\left(\widetilde{\theta}\left(E\left\{\theta_{1}\right\}\right)\right)
\end{aligned}
$$

and

$$
\begin{aligned}
\Pi_{1}^{*}(\tilde{\theta}(\underline{\theta})) & =\int_{\underline{\theta}}^{\bar{\theta}} \pi^{d}(z, \tilde{\theta}(\underline{\theta})) d F(z) \\
& >\int_{\underline{\theta}}^{\bar{\theta}}\left(x^{d}(z, \widetilde{\theta}(\underline{\theta}))+\frac{\beta^{2}\left(z-E\left\{\theta_{1}\right\}\right)}{2\left(4-\beta^{2}\right)}\right)^{2} d F(z)=\Pi_{1}^{o}(\widetilde{\theta}(\underline{\theta}))
\end{aligned}
$$

The existence of the critical value $\theta^{o}$, with $\widetilde{\theta}(\underline{\theta})<\theta^{o}<\widetilde{\theta}\left(E\left\{\theta_{1}\right\}\right)$, follows directly from the monotonicity of the expected profit difference $\Pi_{1}^{o}\left(\theta_{2}\right)-\Pi_{1}^{*}\left(\theta_{2}\right)$, and the observations $\Pi_{1}^{o}\left(\widetilde{\theta}\left(E\left\{\theta_{1}\right\}\right)\right)-\Pi_{1}^{*}\left(\widetilde{\theta}\left(E\left\{\theta_{1}\right\}\right)\right)>0$ and $\Pi_{1}^{o}(\tilde{\theta}(\underline{\theta}))-\Pi_{1}^{o}(\tilde{\theta}(\underline{\theta}))<0$. 


\section{Proof of Proposition 2}

The proof is similar to the proof of Proposition 1.

First, if $\widetilde{\theta}\left(E\left\{\theta_{1}\right\}\right) \leq \theta_{2}<\widetilde{\theta}(\bar{\theta})$, then:

$$
S^{*}\left(\theta_{2}\right)-S^{o}\left(\theta_{2}\right)=\int_{\tilde{\theta}^{-1}\left(\theta_{2}\right)}^{\bar{\theta}}\left[S\left(x^{d}\left(z, \theta_{2}\right), x^{d}\left(\theta_{2}, z\right)\right)-S\left(x^{m}(z), 0\right)\right] d F(z)
$$

and

$$
\begin{aligned}
\frac{d\left[S^{o}\left(\theta_{2}\right)-S^{*}\left(\theta_{2}\right)\right]}{d \theta_{2}}= & \left.\frac{\widetilde{d \theta}^{-1}\left(\theta_{2}\right)}{d \theta_{2}}\left[S\left(x^{m}\left(\theta_{1}\right), 0\right)-S\left(x^{d}\left(\theta_{1}, \theta_{2}\right), x^{d}\left(\theta_{2}, \theta_{1}\right)\right)\right] f\left(\theta_{1}\right)\right|_{\theta_{1}=\tilde{\theta}^{-1}\left(\theta_{2}\right)} \\
& +\int_{\tilde{\theta}^{-1}\left(\theta_{2}\right)}^{\bar{\theta}} \frac{d S\left(x^{d}\left(z, \theta_{2}\right), x^{d}\left(\theta_{2}, z\right)\right)}{d \theta_{2}} d F(z) \\
= & \int_{\tilde{\theta}^{-1}\left(\theta_{2}\right)}^{\bar{\theta}} \frac{d S\left(x^{d}\left(z, \theta_{2}\right), x^{d}\left(\theta_{2}, z\right)\right)}{d \theta_{2}} d F(z)<0
\end{aligned}
$$

since $S\left(x^{m}\left(\theta_{1}\right), 0\right)=S\left(x^{d}\left(\theta_{1}, \theta_{2}\right), x^{d}\left(\theta_{2}, \theta_{1}\right)\right)$ for $\theta_{1}=\widetilde{\theta}^{-1}\left(\theta_{2}\right)$, and

$$
\begin{aligned}
\frac{d S\left(x^{d}\left(\theta_{1}, \theta_{2}\right), x^{d}\left(\theta_{2}, \theta_{1}\right)\right)}{d \theta_{2}} & =\sum_{\substack{i, j \in\{1,2\} \\
j \neq i}} \frac{\partial x^{d}\left(\theta_{i}, \theta_{j}\right)}{\partial \theta_{2}}\left[x^{d}\left(\theta_{i}, \theta_{j}\right)+\beta x^{d}\left(\theta_{j}, \theta_{i}\right)\right] \\
& =\frac{-\beta}{4-\beta^{2}} x^{d}\left(\theta_{1}, \theta_{2}\right)-\frac{2-\beta^{2}}{4-\beta^{2}} x^{d}\left(\theta_{2}, \theta_{1}\right)<0
\end{aligned}
$$

for all $\theta_{1}>\widetilde{\theta}^{-1}\left(\theta_{2}\right)$. Consequently, $S^{*}\left(\theta_{2}\right)-S^{o}\left(\theta_{2}\right)>S^{*}(\widetilde{\theta}(\bar{\theta}))-S^{o}(\widetilde{\theta}(\bar{\theta}))=0$.

Second, take $\widetilde{\theta}(\underline{\theta}) \leq \theta_{2}<\widetilde{\theta}\left(E\left\{\theta_{1}\right\}\right)$. For these parameter values the consumer surpluses under information sharing and information concealment are, respectively:

$$
\begin{aligned}
& S^{*}\left(\theta_{2}\right)=\int_{\underline{\theta}}^{\widetilde{\theta}^{-1}\left(\theta_{2}\right)} S\left(x^{m}(y), 0\right) d F(y)+\int_{\tilde{\theta}^{-1}\left(\theta_{2}\right)}^{\bar{\theta}} S\left(x^{d}\left(z, \theta_{2}\right), x^{d}\left(\theta_{2}, z\right)\right) d F(z) \\
& S^{o}\left(\theta_{2}\right)=E\left\{S\left(x^{d}\left(\theta_{1}, \theta_{2}\right)+\frac{\beta^{2}\left(\theta_{1}-E\left\{\theta_{1}\right\}\right)}{2\left(4-\beta^{2}\right)}, x^{d}\left(\theta_{2}, E\left\{\theta_{1}\right\}\right)\right)\right\}
\end{aligned}
$$

The first derivative of $S^{*}\left(\theta_{2}\right)$ equals:

$$
\begin{aligned}
\frac{d S^{*}\left(\theta_{2}\right)}{d \theta_{2}}= & \frac{\widetilde{d \theta}^{-1}\left(\theta_{2}\right)}{d \theta_{2}}\left[S\left(x^{m}\left(\widetilde{\theta}^{-1}\left(\theta_{2}\right)\right), 0\right)-S\left(x^{d}\left(\widetilde{\theta}^{-1}\left(\theta_{2}\right), \theta_{2}\right), x^{d}\left(\theta_{2}, \widetilde{\theta}^{-1}\left(\theta_{2}\right)\right)\right)\right] f\left(\widetilde{\theta}^{-1}\left(\theta_{2}\right)\right) \\
& +\int_{\widetilde{\theta}^{-1}\left(\theta_{2}\right)}^{\bar{\theta}} \frac{d S\left(x^{d}\left(z, \theta_{2}\right), x^{d}\left(\theta_{2}, z\right)\right)}{d \theta_{2}} d F(z) \\
= & \int_{\widetilde{\theta}^{-1}\left(\theta_{2}\right)}^{\bar{\theta}} \frac{d S\left(x^{d}\left(z, \theta_{2}\right), x^{d}\left(\theta_{2}, z\right)\right)}{d \theta_{2}} d F(z)
\end{aligned}
$$


since $x^{m}\left(\widetilde{\theta}^{-1}\left(\theta_{2}\right)\right)=x^{d}\left(\widetilde{\theta}^{-1}\left(\theta_{2}\right), \theta_{2}\right)$. Taking the first derivative of $S^{o}\left(\theta_{2}\right)$ yields:

$$
\begin{aligned}
\frac{d S^{o}\left(\theta_{2}\right)}{d \theta_{2}} & =\int_{\underline{\theta}}^{\bar{\theta}} \frac{d S\left(x^{d}\left(z, \theta_{2}\right)+\frac{\beta^{2}\left(z-E\left\{\theta_{1}\right\}\right)}{2\left(4-\beta^{2}\right)}, x^{d}\left(\theta_{2}, E\left\{\theta_{1}\right\}\right)\right)}{d \theta_{2}} d F(z) \\
& =\int_{\underline{\theta}}^{\bar{\theta}} \frac{d S\left(x^{d}\left(z, \theta_{2}\right), x^{d}\left(\theta_{2}, z\right)\right)}{d \theta_{2}} d F(z)
\end{aligned}
$$

The comparison of first derivatives gives:

$$
\frac{d S^{o}\left(\theta_{2}\right)}{d \theta_{2}}-\frac{d S^{*}\left(\theta_{2}\right)}{d \theta_{2}}=\int_{\underline{\theta}}^{\widetilde{\theta}^{-1}\left(\theta_{2}\right)} \frac{d S\left(x^{d}\left(z, \theta_{2}\right), x^{d}\left(\theta_{2}, z\right)\right)}{d \theta_{2}} d F(z)<0
$$

since $d S\left(x^{d}\left(\theta_{1}, \theta_{2}\right), x^{d}\left(\theta_{2}, \theta_{1}\right)\right) / d \theta_{2}<0$ for all $\theta_{1} \leq \widetilde{\theta}^{-1}\left(\theta_{2}\right)$ and $\theta_{2}<\tilde{\theta}\left(E\left\{\theta_{1}\right\}\right)$. The evaluation of the consumer surpluses for extreme values of firm 2's cost gives the following:

$$
\begin{aligned}
S^{*}\left(\widetilde{\theta}\left(E\left\{\theta_{1}\right\}\right)\right) & =\int_{\underline{\theta}}^{E\left\{\theta_{1}\right\}} S\left(x^{m}(\theta), 0\right) d F(\theta)+\int_{E\left\{\theta_{1}\right\}}^{\bar{\theta}} S\left(x^{d}\left(z, \theta_{2}\right), x^{d}\left(\theta_{2}, z\right)\right) d F(z) \\
& >\int_{\underline{\theta}}^{\bar{\theta}} S\left(x^{m}(z), 0\right) d F(z)=S^{o}\left(\widetilde{\theta}\left(E\left\{\theta_{1}\right\}\right)\right)
\end{aligned}
$$

and

$$
\begin{aligned}
S^{*}(\tilde{\theta}(\underline{\theta})) & =\int_{\underline{\theta}}^{\bar{\theta}} S\left(x^{d}(z, \tilde{\theta}(\underline{\theta})), x^{d}(\widetilde{\theta}(\underline{\theta}), z)\right) d F(z) \\
& <\int_{\underline{\theta}}^{\bar{\theta}} S\left(x^{d}(z, \widetilde{\theta}(\underline{\theta}))+\frac{\beta^{2}\left(z-E\left\{\theta_{1}\right\}\right)}{2\left(4-\beta^{2}\right)}, x^{d}\left(\widetilde{\theta}(\underline{\theta}), E\left\{\theta_{1}\right\}\right)\right) d F(z)=S^{o}(\widetilde{\theta}(\underline{\theta}))
\end{aligned}
$$

The existence of the critical value $\theta^{o}$, with $\widetilde{\theta}(\underline{\theta})<\theta^{*}<\widetilde{\theta}\left(E\left\{\theta_{1}\right\}\right)$, follows directly from the monotonicity of the expected profit difference $S^{o}\left(\theta_{2}\right)-S^{*}\left(\theta_{2}\right)$, and the observations $S^{o}\left(\widetilde{\theta}\left(E\left\{\theta_{1}\right\}\right)\right)-S^{*}\left(\widetilde{\theta}\left(E\left\{\theta_{1}\right\}\right)\right)<0$ and $S^{o}(\tilde{\theta}(\underline{\theta}))-S^{o}(\widetilde{\theta}(\underline{\theta}))>0$.

\section{Proof of Proposition 3}

The proof is similar to standard proofs of the unravelling result.

Suppose that firm 2 holds skeptical beliefs, i.e. $E\left\{\theta_{1} \mid \varnothing\right\}=\bar{\theta}$. Given these beliefs, firm 1 earns higher profits under information disclosure than under concealment, since $x_{1}^{*}\left(\theta_{1}, \theta_{2}\right)>x_{1}^{o}\left(\theta_{1}, \theta_{2} ; \bar{\theta}\right)$ for all $\theta_{1} \in[\underline{\theta}, \bar{\theta})$, and $x_{1}^{*}\left(\theta_{1}, \theta_{2}\right)=x_{1}^{o}\left(\theta_{1}, \theta_{2} ; \bar{\theta}\right)$ for $\theta_{1}=\bar{\theta}$. Notice that the beliefs are consistent with the information disclosure incentives. 


\section{Proof of Proposition 4}

Suppose $\tilde{\theta}\left(E\left\{\theta_{1}\right\}\right) \leq \theta_{2}<\tilde{\theta}(\bar{\theta})$, and $\mathcal{D} \subset\left[\underline{\theta}, \tilde{\theta}^{-1}\left(\theta_{2}\right)\right]$ is such that $E\left\{\theta_{1} \mid \theta_{1} \notin \mathcal{D}\right\} \leq$ $\tilde{\theta}^{-1}\left(\theta_{2}\right)$. Further, suppose that firm 2 holds beliefs consistent with disclosure rule (17). In that case $\theta_{2}=\widetilde{\theta}\left(\widetilde{\theta}^{-1}\left(\theta_{2}\right)\right) \geq \widetilde{\theta}\left(E\left\{\theta_{1} \mid \theta_{1} \notin \mathcal{D}\right\}\right)$, and therefore firm 1 receives the profit $\pi^{m}\left(\theta_{1}\right)$ under concealment. For all $\theta_{1} \leq \widetilde{\theta}^{-1}\left(\theta_{2}\right)$ the profit from disclosure of $\theta_{1}$ is $\pi_{1}^{*}\left(\theta_{1}, \theta_{2}\right)=\pi^{m}\left(\theta_{1}\right)$, and therefore disclosure of $\theta_{1} \in \mathcal{D}$ and concealment of $\theta_{1} \in\left[\underline{\theta}, \widetilde{\theta}^{-1}\left(\theta_{2}\right)\right] \backslash \mathcal{D}$ is optimal. For all $\theta_{1}>\widetilde{\theta}^{-1}\left(\theta_{2}\right)$ the profit from disclosure is $\pi_{1}^{*}\left(\theta_{1}, \theta_{2}\right)=x^{d}\left(\theta_{1}, \theta_{2}\right)^{2}<\pi^{m}\left(\theta_{1}\right)$, and concealment is optimal. Hence, any type $\theta_{1} \notin \mathcal{D}$ has an incentive to conceal, and any type $\theta_{1} \in \mathcal{D}$ has an incentive to disclose.

\section{References}

FRIED, D. (1984) "Incentives for Information Production and Disclosure in a Duopolistic Environment", Quarterly Journal of Economics 99, 367-381

GAL-OR, E. (1986) "Information Transmission - Cournot and Bertrand Equilibria", Review of Economic Studies 53, 85-92

Grossman, S.J. (1981) "The Informational Role of Warranties and Private Disclosure about Product Quality", Journal of Law and Economics 24, 461-483

KÜHn, K-U. AND X. Vives (1995) "Information Exchange among Firms and their Impact on Competition", Luxembourg: Office for Official Publications of the European Communities

Milgrom, P.R. (1981) "Good News and Bad News: Representation Theorems and Applications", Bell Journal of Economics 12, 380-91

Okuno-Fujiwara, M., Postlewaite A. And K. Suzumura (1990) "Strategic Information Revelation", Review of Economic Studies 57, 25-47

Shapiro, C. (1986) "Exchange of Cost Information in Oligopoly", Review of Economic Studies 53, 433-446

Vives, X. (1999) "Oligopoly Pricing: Old Ideas and New Tools", Cambridge, MA: MIT Press 


\section{Preprints 2009}

2009/31: Fellner G., Sausgruber R., Traxler C., Testing Enforcement Strategies in the Field: Legal Threat, Moral Appeal and Social Information

2009/30: Lüdemann J., Rechtsetzung und Interdisziplinarität in der Verwaltungsrechtswissenschaft

forthcoming in: Öffentliches Recht und Wissenschaftstheorie, Funke A., Lüdemann J., (Eds.), Tübingen, Mohr Siebeck, pp. 125-150

2009/29: Engel C., Rockenbach B., We Are Not Alone: The Impact of Externalities on Public Good Provision

2009/28: Gizatulina A., Hellwig M., Informational Smallness and the Scope for Limiting Information Rents

2009/27: Hahmeier M., Prices versus Quantities in Electricity Generation

2009/26: Burhop C., The Transfer of Patents in Imperial Germany

2009/25: Burhop C., Lübbers T., The Historical Market for Technology Licenses: Chemicals, Pharmaceuticals, and Electrical Engineering in Imperial Germany

2009/24: Engel C., Competition as a Socially Desirable Dilemma Theory vs. Experimental Evidence

2009/23: Morell A., Glöckner A., Towfigh E., Sticky Rebates: Rollback Rebates Induce Non-Rational Loyalty in Consumers Experimental Evidence

2009/22: Traxler C., Majority Voting and the Welfare Implications of Tax Avoidance

2009/21: Beckenkamp M., Engel C., Glöckner A., Irlenbusch B., Hennig-Schmidt H., Kube S., Kurschilgen M., Morell A., Nicklisch A., Normann H., Towfigh E., Beware of Broken Windows! First Impressions in Public-good Experiments

2009/20: Nikiforakis N., Normann H., Wallace B., Asymmetric Enforcement of Cooperation in a Social Dilemma forthcoming in: Southern Economic Review, In Press.

2009/19: Magen S., Rechtliche und ökonomische Rationalität im Emissionshandelsrecht

2009/18: Broadberry S.N., Burhop C., Real Wages and Labour Productivity in Britain and Germany, 1871-1938: A Unified Approach to the International Comparison of Living Standards

2009/17: Glöckner A., Hodges S.D., Parallel Constraint Satisfaction in Memory-Based Decisions

2009/16: Petersen N., Review Essay: How Rational is International Law? forthcoming in: European Journal of International Law, vol. 20, In Press.

2009/15: Bierbrauer F., On the legitimacy of coercion for the financing of public goods

2009/14: Feri F., Irlenbusch B., Sutter M., Efficiency Gains from Team-Based Coordination - Large-Scale Experimental Evidence

2009/13: Jansen J., On Competition and the Strategic Management of Intellectual Property in Oligopoly

2009/12: Hellwig M., Utilitarian Mechanism Design for an Excludable Public Good

published in: Economic Theory, vol. 2009, no. July 14, Berlin/Heidelberg, Springer, 2009.

2009/11: Weinschenk P., Persistence of Monopoly and Research Specialization

2009/10: Horstmann N., Ahlgrimm A., Glöckner A., How Distinct are Intuition and Deliberation? An Eye-Tracking Analysis of Instruction-Induced Decision Modes

2009/09: Lübbers T., Is Cartelisation Profitable? A Case Study of the Rhenish Westphalian Coal Syndicate, 1893-1913 
2009/08: Glöckner A., Irlenbusch B., Kube S., Nicklisch A., Normann H., Leading with(out) Sacrifice?

A Public-Goods Experiment with a Super-Additive Player

forthcoming in: Economic Inquiry, In Press.

2009/07: von Weizsäcker C., Asymmetrie der Märkte und Wettbewerbsfreiheit

2009/06: Jansen J., Strategic Information Disclosure and Competition for an Imperfectly Protected Innovation forthcoming in: Journal of Industrial Economics, In Press.

2009/05: Petersen N., Abkehr von der internationalen Gemeinschaft? - Die aktuelle Rechtsprechung des US Supreme Court zur innerstaatlichen Wirkung von völkerrechtlichen Verträgen -

forthcoming in: Völkerrecht im innerstaatlichen Bereich, Vienna, facultas.wuv, In Press.

2009/04: Rincke J., Traxler C., Deterrence Through Word of Mouth

2009/03: Traxler C., Winter J., Survey Evidence on Conditional Norm Enforcement

2009/02: Herbig B., Glöckner A., Experts and Decision Making: First Steps Towards a Unifying Theory of Decision Making in Novices, Intermediates and Experts

2009/01: Beckenkamp M., Environmental dilemmas revisited: structural consequences from the angle of institutional ergonomics, issue 2009/01

\section{Preprints 2008}

2008/49: Glöckner A., Dickert S., Base-rate Respect by Intuition: Approximating Rational Choices in Base-rate Tasks with Multiple Cues

2008/48: Glöckner A., Moritz S., A Fine-grained Analysis of the Jumping to Conclusions Bias in Schizophrenia: DataGathering, Response Confidence, and Information Integration

2008/47: Hellwig M., A Generalization of the Atkinson-Stiglitz (1976) Theorem on the Undesirability of Nonuniform Excise Taxation

2008/46: Burhop C., The Underpricing of Initial Public Offerings in Imperial Germany, 1870-1896

forthcoming in: German Economic Review, In Press.

2008/45: Hellwig M., A Note on Deaton's Theorem on the Undesirability of Nonuniform Excise Taxation forthcoming in: Economics Letters, In Press.

2008/44: Hellwig M., Zur Problematik staatlicher Beschränkungen der Beteiligung und der Einflussnahme von Investoren bei großen Unternehmen published in: Zeitschrift für das gesamte Handelsrecht und Wirtschaftsrecht, vol. 172, pp. 768-787, 2008.

2008/43: Hellwig M., Systemic Risk in the Financial Sector: An Analysis of the Subprime-Mortgage Financial Crisis published in: De Economist, no. 16.07.2009: Springer US, 2009.

published in: Jelle Zijlstra Lecture, no. 2008/5, Wassenaar, NL, Netherlands Institute for Advanced Study in the Humanities and Social Sciences, Institute of the Royal Netherlands Academy of Arts and Sciences, pp. 100, 2008.

2008/42: Glöckner A., Herbold A., Information Processing in Decisions under Risk: Evidence for Compensatory Strategies based on Automatic Processes

2008/41: Lüdemann J., Magen S., Effizienz statt Gerechtigkeit forthcoming in: Zeitschrift für Rechtsphilosophie, In Press.

2008/40: Engel C., Die Bedeutung der Verhaltensökonomie für das Kartellrecht 